tence of always being in the right. "I couldn't have been more wrong", he says at one point. Nor of always claiming success. U Thant once sent him inscribed copies of reports he, Zuckerman, had written on arms control for the UN, about which he writes: "Despite their wide circulation I never did learn if any one of them had much effect on world opinion. The way the arms race has proceeded over the past decades I would think not".

However it is when he comes to nuclear weapons that most readers may well find his story at its most gripping. In a crucial passage he states another of his propositions:

The state of mutual strategic deterrence, upheld by the threat of retaliation with nuclear weapons, will remain valid until (1) a meaningful defence is achieved against both ballistic missiles and low-flying aircraft... or (2) a weapons delivery system is perfected which, for all practical purposes, could successfully carry out a surprise attack which destroyed so large a proportion of the other side's delivery system before they could be launched, as to make it impossible to make a retaliatory strike. [It was]... just technically possible, but immensely expensive in resources to devise an anti-ballistic missile capable of intercepting the simplest kind of incoming warhead.... But the balance is inevitably in favour of the attacker, and no Western scientist or technologist knows a way of providing an anti-ballistic missile defence of the major targets in his country. If the Russians know of one, we had no idea what it is.

Twenty five years later that remains my view, SDI or no SDI. The state of mutual deterrence is likely to remain valid indefinitely.

It is clear that Zuckerman is entirely convinced of the use of nuclear weapons in their role of deterrent: equally clear is that his confidence in their use in the cause of military strategy is nil. In this latter view he came of course into conflict with those weaponeers who, having 'perfected' their nuclear weapons, felt - and no doubt still feel, human nature being, alas, what it is - an irresistible urge to fire them off. He describes an encounter with Edward Teller, whom many people regard as the Evil Genius of The Bomb - in part responsible for its totally unnecessary use on Nagasaki, then fighting any moves whatsoever to ban test explosions, then shifting ground to propose the use of just little nuclear bombs on the battlefield, and finally as a last resort developing a case for exploiting nuclear bombs to make big holes in the ground. Zuckerman records the stormy meeting at which first he, and then Lord Mountbatten, denounced Teller's proclamations (about battlefield weapons) as dangerous military nonsense:

During a break in the proceedings, I was sitting chatting in the sunshine with some uniformed friends, when Teller came up to me, and, in his strange accent, said, 'I will not forgive you for that, to which I replied that it would make not the slightest difference to me if he didn't. I knew that nothing could stop him. To this day

he continues to expound what to me is dangerous military and political nonsense.

It should not go without remark that Zuckerman in those days received a great deal of support and wise advice from Harold Macmillan, who was then Prime Minister. But in 1964 it was decided to 'reform' the loose components of the Ministry of Defence into a huge new 'super-department'. Thus:

I nonetheless feared that the bureaucratic procedure he was suggesting could slow down action, particularly when minutes from my side of the Ministry were pored over by people who could not understand their scientific and technological significance... Nor was I ready to surrender my right to say what I wanted, regardless of the views of the rest of the Ministry, and even those of my staff. This manifesto in favour of free speech was in the end to bring about my departure from the department.

Shortly afterwards Harold Wilson came to power, and wanted Zuckerman to go to the Foreign Office (with a peerage) as

\section{Soviet star-turns}

\section{Desmond King-Hele}

Race into Space: The Soviet Space Programme. By Brian Harvey. Ellis Horwood: 1988. Pp. 381. £16.95, \$39.95.

Future historians may well rate the Soviet effort in space exploration as one of the greatest technological achievements of the twentieth century. The launching of Sputnik 1 in 1957 came as a great surprise to Western nations basking in the selfesteem engendered by their more advanced technology. That surprise has ripened into embarrassment as the sustained momentum of the Soviet programme has become evident.

If the journalistic cliché of a 'space race' is accepted, as in the title of Brian Harvey's book, it is a race in which one runner has already lapped all the rest: in the ten years from 1978 to 1987 there were 933 space launches by the Soviet Union (excluding Intercosmos), 146 by the United States (excluding international launches such as Intelsat), 24 by Japan and lesser numbers by others. Awkward statistics like these are conveniently ignored on the rare occasions when Soviet launches are reported in the West: we are usually told that the Soviets are beginning to catch up the Americans, and most people accept this perversion of reality, so awesome is the power of persistent propaganda.

Although there have been failures in the Soviet programme, the fact is that the Mir space-station with six docking points has been in operation since 1986: crews have been interchanged from time to time; there have been numerous visits
Minister of State for Disarmament. He turned it down, wanting to remain a scientist rather than to become a politician. (Yet, some years later, he wondered if he could have achieved more for disarmament by accepting.) Instead he became Chief Scientific Adviser to the Government, lodged in the Cabinet Office. In this new role he held a succession of jobs over a wide range of scientific interest, environmental and so on. Yet a preoccupation with nuclear affairs has remained nearest to his heart. When the time came for retirement he accepted a peerage from the then Prime Minister, Edward Heath. And in 1982, still on his lasting theme, he wrote a book called Nuclear Illusion and Reality - which, one imagines, does not find entire favour with the now Prime Minister.

William Cooper, Savile Club, 69 Brook Street London WIY 2ER, UK, is the pseudonym of the novelist Harry Hoff. From 1958 to 1972 he was personnel consultant to the United Kingdom Atomic Energy Authority.

by short-stay cosmonauts; unmanned 'Progress' craft have called regularly to deliver supplies and remove rubbish; scientific experiments have been pursued aboard Mir and through modules like Qvant, attached at spare docking ports. Already there is an orbital community, with people and supplies brought in and out not by car and truck but by advanced vehicles appropriate to the environment. At present, living in space is neither spacious nor gracious: the living quarters are cramped, and most crews are all-male. But both of these limitations will gradually be relaxed if Mir succeeds in avoiding the ever-present threat of disaster (for example, from being struck by debris). We should then see larger space habitats with better-balanced populations. The Mir programme is also an impressive act of faith in the future good behaviour of humankind. 'Mir' means 'peace', and Mir needs peace, because this most expensive project can be ruined by any hostile power that chooses to detonate debris-creating weapons in orbit at the appropriate height.

Why has the Soviet Union devoted so much effort to space exploration, by comparison with the United States, which took the lead with the manned Moon landings in 1969-1972 and then seemed to lose interest? The easy answer is that the Soviet Union has had consistent government and long-term planning, while the United States suffers from the hot and cold turns of its electorate, and was lured into building a space shuttle for travelling between Earth and a space station that had already been cancelled. (Another is now being proposed, to give the shuttle a role.)

This answer has some validity, but does not tell us why the Soviets have been and 
still are so keen. One of the best features of Race into Space is the attempt to explain the impetus in historical terms. The inspiration came from Konstantin Tsiolkovsky (1857-1935) who, in books such as $A$ Dream of Earth and $S k y$ (1895), foresaw nearly all of the events that have actually occurred. He advocated liquid-fuel engines, the staging of rockets, solar power and even stellar ships with closed ecocycles. Surprising as it may seem to those living in Western countries, where rocket enthusiasts were scorned until after 1940 , Tsiolkovsky was encouraged by the state; he was given a pension in 1918 , and

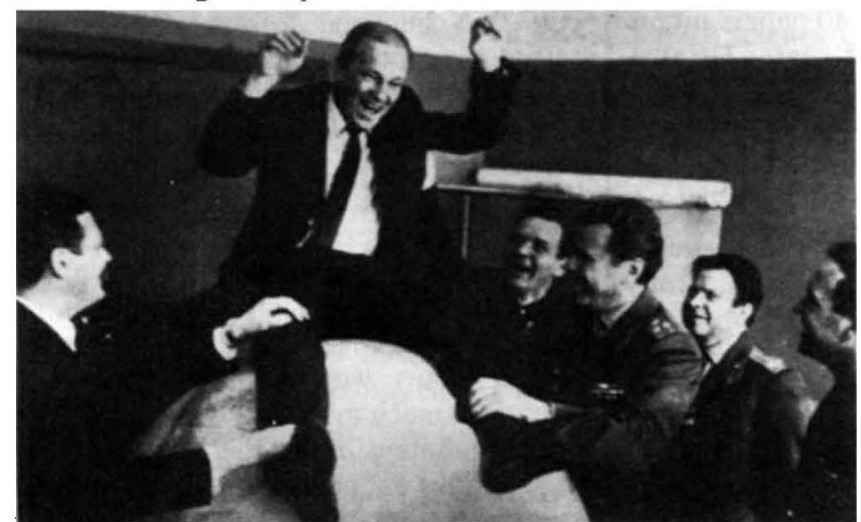

On top of the world - the cosmonauts involved in the Salyut 1 mission. The picture is reproduced from The Soviet Manned Space Programme by Phillip Clark, Publisher is Salamander, price is $£ 14.95$.

a meeting of the Academy of Sciences was held in his honour in 1932. His home was to become a place of pilgrimage. Scientific achievement (unsullied by the profit motive) was held dear by the Soviet government in the 1920 s and early 1930 s, when the engineer Frederick Tsander (1887-1933) constructed liquid-fuel rockets, the author Yuri Kondratyuk foresaw the future course of space exploration, and research institutes for jet propulsion and aerodynamics were established. "By the mid 1920s, all the major components of the Soviet space programme were in place", Harvey remarks, and it seems a defensible claim. But the programme ran into the sands, because of policy changes and Stalin's purges - among those imprisoned was Sergei Korolov (1906-1966), later the 'chief designer' of space launchers. After the Second World War, when the German V2 showed everyone what could have been done, Soviet rocket development went ahead strongly. The desire for military rockets was the driving force, but their possible use for space launching was quickly recognized, and exploited by Khruschev from 1954 onwards.

After this historical chapter, Race into Space becomes a detailed narrative, seen always in terms of rivalry with the United States, of Soviet manned spaceflight and lunar and planetary exploration. Only a few pages are devoted to the many other types of satellites that make up the great majority of the Soviet space launches.
There is very little about the photographic reconnaissance satellites, of which nearly a thousand have been launched, or about the many satellites for ocean surveillance, electronic ferreting and early warning. The systems of satellites for communications, meteorology and navigation are only glanced at, and there is scarcely a mention of the numerous spacecraft carrying scientific experiments.

The strength of the book is in its detailed accounts of the out-and-back journeys of the cosmonauts, all of whom are mentioned by name. Not all have been Soviet citizens: they have come from many different countries, ranging alphabetically from Bulgaria and Cuba to Syria and Vietnam (with Afghanistan as a recent addition). With so many flights to be covered, the details of the crews may seem almost as boring as a roster of bus drivers leaving and returning to their depot. Harvey recognizes this problem and tries to enliven the text with character-sketches of some of the cosmonauts and overdone dramatizations. For example, there is the story of the US astronauts arriving by airliner at "Star City': "out jumped the three Americans", we are told, and after this improbable gymnastic feat they drive in a minibus past "endless avenues" in this city surrounded by desert, "endless, flat and arid", with a river running through it. Wet or dry, the style is not flat, and the adjectives are as endless as the avenues or the desert. At the other extreme, the crew of Voskhod2, landing at night, had to endure "frosty breath from lurking shadowy forms" (these are wolves, not the welcoming party).

There are plenty of photographs, not of wolves, but chiefly of cosmonauts, who all look remarkably similar in space suits, especially as the quality of the photographs is poor. Also there are no diagrams in the main text, and the author is left with the unenviable task of trying to describe in words the complex design of Mir. All in all, the book does provide a useful, detailed account of Soviet manned spaceflight and lunar and planetary exploration, though the style may deter some wouldbe readers and minor inaccuracies are numerous.

Desmond King-Hele, 3 Tor Road, Farnham, Surrey $G U 97 B X, U K$, was formerly a Deputy Chief Scientific Officer at the Royal Aircraft Establishment, Farnborough. Among other books he is author of Satellites and Scientific Research (1960) and Satellite Orbits in an Atmosphere (1987).

\section{Arp's astronomical exotica}

\section{Michael Rowan-Robinson}

Quasars, Redshifts and Controversies. By Halton Arp. Interstellar Media, 2153 Russell Street, Berkeley, California 94705/ Cambridge University Press:1988. Pp.198. $\$ 22.20, £ 12.50$.

IN 1966 Halton Arp compiled one of the most fascinating catalogues of modern astronomy, the Arp Atlas of Peculiar and Interacting Galaxies. For nearly 20 years the remarkable objects in this catalogue were for the most part ignored by astronomers, who continued to think of galaxies as basically regular-shaped spirals or ellipticals. Now, in the past five years, interactions and mergers between pairs of galaxies have leapt to the forefront of the astronomical consciousness, partly because of the growth in sophistication of computer simulations of the dynamical interactions between galaxies, and partly because a higher than expected proportion of luminous infrared galaxies appear to be due to interactions or mergers.

But Arp will not be able to enjoy this tribute to his perspicacity. For as he was preparing his Atlas for publication, he noticed that some of the sources in the Third Cambridge Survey of Radio Sources appeared to lie in pairs on opposite sides of some of his peculiar galaxies. Because the recession velocities of the radiogalaxies and quasars with which these sources were identified were in general enormously larger than those of the "associated' peculiar galaxies, not only must the Hubble velocity-distance law break down in some circumstances but galaxies must be capable of spewing out whole galaxies and quasars.

This discovery took Arp down an extraordinary trail of quasars associated with nearby galaxies, companion galaxies with excess redshift, chains of galaxies with discordant redshifts, to quasars as members of the Local Group of galaxies. Because quasars were at that time so novel and incomprehensible many astronomers, myself included, were at first willing to keep an open mind about Arp's associations and to follow him at least a little way down the trail. Could the quasars, for example, like the nebulae before them, comprise more than one completely distinct kind of object?

Gradually, the possibility of there being any serious basis to Arp's claims dissolved. Quasars were found to be situated in galaxies and were often found to be in groups or clusters of galaxies which had the same redshift as the quasar. Statistically controlled surveys for quasars showed them to be distributed homogeneously 